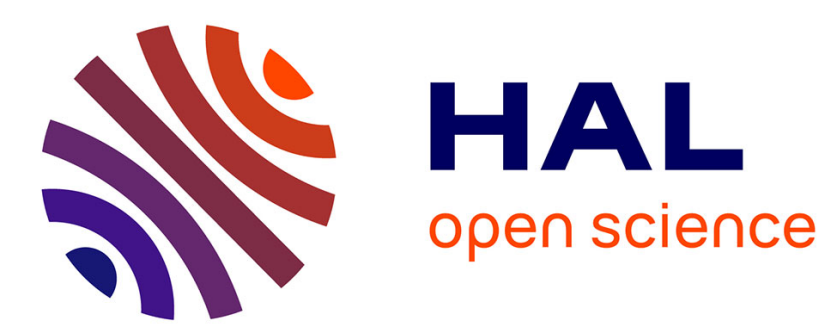

\title{
Simulation of the reinforcement compaction and resin flow during the complete resin infusion process
}

\author{
Quentin Govignon, S. Bickerton, P.A. Kelly
}

\section{To cite this version:}

Quentin Govignon, S. Bickerton, P.A. Kelly. Simulation of the reinforcement compaction and resin flow during the complete resin infusion process. Composites Part A: Applied Science and Manufacturing, 2010, 41 (1), pp.45-57. 10.1016/j.compositesa.2009.07.007 . hal-02070802

\section{HAL Id: hal-02070802 https://hal.science/hal-02070802}

Submitted on 29 Nov 2019

HAL is a multi-disciplinary open access archive for the deposit and dissemination of scientific research documents, whether they are published or not. The documents may come from teaching and research institutions in France or abroad, or from public or private research centers.
L'archive ouverte pluridisciplinaire HAL, est destinée au dépôt et à la diffusion de documents scientifiques de niveau recherche, publiés ou non, émanant des établissements d'enseignement et de recherche français ou étrangers, des laboratoires publics ou privés. 


\title{
Simulation of the reinforcement compaction and resin flow during the complete resin infusion process
}

\author{
Q. Govignon ${ }^{\mathrm{a}}$, S. Bickerton ${ }^{\mathrm{a}, *}$, P.A. Kelly ${ }^{\mathrm{b}}$ \\ ${ }^{a}$ Centre for Advanced Composite Materials, Department of Mechanical Engineering, The University of Auckland, Private Bag 92019, Auckland 1020, New Zealand \\ ${ }^{\mathrm{b}}$ Centre for Advanced Composite Materials, Department of Engineering Science, The University of Auckland, Private Bag 92019, Auckland 1020, New Zealand
}

Keywords:

Resin infusion

C. Finite element analysis (FEA)

E. Resin flow

E. Preform

\begin{abstract}
A B S T R A C T
Resin infusion (a.k.a. VARTM) is one of the LCM processes, for which liquid resin is drawn into dry reinforcements. Significant cavity thickness changes occur during processing, due to the flexibility of the vacuum bag used as one side of the tool, and the complex stress balance within the laminate. While the magnitude of thickness change is often small, the influence is significant on reinforcement properties. Changes in permeability during filling and post-filling have the potential to significantly affect the process. To simulate this behaviour, it is important to accurately model compaction and unloading of reinforcement in dry and wet states. A series of tests were completed to determine compaction behaviour of an isotropic glass fibre mat. From these tests several non-linear elastic compaction models have been determined, and applied within a resin infusion simulation which addresses pre-filling, filling and post-filling. This simulation was then used to assess different post-filling strategies.
\end{abstract}

\section{Introduction}

Resin infusion (RI) is part of the Liquid Composite Moulding (LCM) process family. The term LCM describes the closed mould processes in which a liquid polymeric resin is impregnated through a fibrous reinforcement. Commonly applied LCM processes include Resin Transfer Moulding (RTM), Injection/Compression Moulding (I/CM a.k.a. CRTM), RTMLight and resin infusion (RI, a.k.a Vacuum Assisted RTM). LCM processes provide good control over harmful volatiles generated by thermoset resins, making them compliant with tougher new environmental standards put in place internationally. The final fibre volume fraction $\left(V_{f}\right)$ achieved can be higher and more consistent than that achieved with traditional open mould techniques. LCM processes also have the potential for automation, greatly reducing labour costs [1-4].

During manufacture with an LCM process, the operator typically has little control over the advancement of the flow, and successful process development by trial and error requires experience and can be long and expensive. Reduction of development costs requires a good understanding of the process physics, and can benefit from development of an accurate simulation tool. Significant effort has been placed into establishment of RTM and I/CM simulations that accurately predict fill time, flow front advancement and dry spot formation [5-11]. These two processes, through the use of rigid mould tools, allow for accurate control of the laminate thick-

\footnotetext{
* Corresponding author.

E-mail address: s.bickerton@auckland.ac.nz (S. Bickerton).
}

ness and therefore of the fibre volume fraction. Current rigid tool simulations can take into account localised phenomena [12-14], predict tooling forces [15,16], and allow for automated process control via integrated sensing and simulation technology $[17,18]$. The accuracy of these tools is dependant on the quality of provided permeability data, permeability quantifying the resistance to resin flow provided by the reinforcement materials comprising the preform. Research is ongoing into accurate measurement and prediction of reinforcement permeability [19-23].

As opposed to the RTM and I/CM processes, RI uses a single sided mould, the reinforcement being contained within a cavity formed and sealed by a vacuum bag. As the vacuum bag employed during the process provides minimal rigidity, the compaction of the fibrous reinforcement is governed by the pressure difference between the inside of the cavity and the external atmospheric pressure. The preform thickness will vary in relation to the resin pressure inside the cavity [24-28], and so will the reinforcement permeability which is governed by the local reinforcement architecture. Fig. 1 describes the components required for application of RI, and the different process stages. Initially, layers of fibrous reinforcement are laid on the mould to create the preform. A layer of peel-ply is generally laid over the preform, allowing for easy separation of the part from the consumables, and provision for a consistent part surface finish. Distribution media can be laid over the peel-ply to enhance resin flow if the reinforcement has low in-plane permeability.

Once inlet and vent tubes are in place, the mould is closed using a vacuum bag sealed with sealant tape. With the cavity sealed, the 


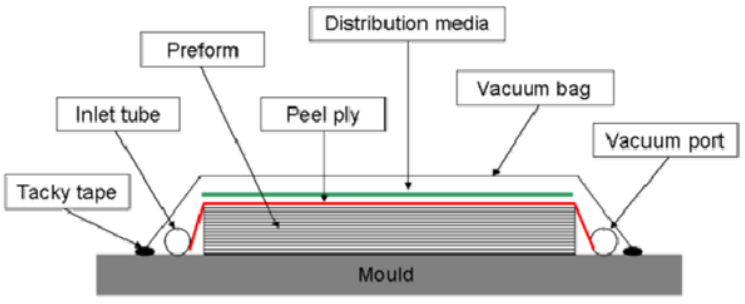

a) Lay up

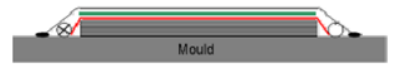

b) Pre-filling

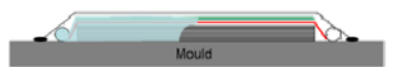

c) Filling

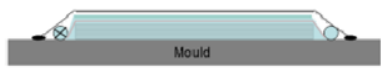

d) Post-filling

Fig. 1. Four stages of the resin infusion process.

inlet is clamped and vacuum is applied to the vents, this stage being referred to here as "pre-filling". At the end of pre-filling, the inlet is opened and the resin penetrates the preform. During this "filling stage", pressure inside the cavity varies in position and time. Once the resin front reaches the end of the preform, the inlet is usually clamped, stopping flow of resin into the cavity. This "post-filling" stage involves removal of excess resin, and allows resin pressure and laminate thickness to equilibrate within the cavity [25]. Once the resin is fully cured, the vacuum is released and the part is lifted off the mould and separated from the consumables. During the full RI process the reinforcement comprising the preform is subjected to a complex deformation history, which is discussed next.

During pre-filling vacuum is applied, and as the pressure differential between the cavity and the atmospheric pressures increases, the reinforcement is subjected to a 'dry compaction' (the dry preform is compacted to a volume fraction higher than the volume fraction at zero stress). The rate of the dry compaction depends on how quickly the pressure differential is allowed to increase. Next comes the filling stage. Note that, before the fluid is injected, the preform will creep, that is, the volume fraction increases under the constant pressure differential. During the filling, within the saturated region, the total compaction pressure applied to the cavity is partly carried by the fluid and partly by the preform. This balance of atmospheric pressure by the fluid pressure and preform compaction stress was expressed by Terzaghi in [29]. The saturated part of the reinforcement is thus subjected to a 'wet unloading', that is, as the local fluid pressure increases, the compaction stress on the reinforcement decreases, and the local fibre volume fraction decreases. During the post-filling, the fluid pressure decreases as the excess resin is drawn out of the cavity. Therefore the preform compaction stress increases and the reinforcement is subjected to a 'wet compaction'. Note that during these three phases (dry compaction, wet unloading and wet compaction) the preform exhibits not just elastic, but viscoelastic deformation traits. The local volume fraction depends not only on the applied compaction stress, but also on the rate at which the applied stress is changing, and these rate effects may be significant. As the permeability is governed by the local reinforcement architecture, accurate simulation of resin infusion requires a realistic model of the reinforcement compaction behaviour.

Amongst the large number of models used for characterising the reinforcement compaction behaviour, the authors would like to review a few significant ones. One of the earliest and most cited works on reinforcement compaction in the RI literature is the paper by Gutowski et al. [30], in which the authors consider the preform to behave as a bundle of aligned wavy beams meeting at multiple contact points. The proposed $\sigma_{f}\left(V_{f}\right)$ relationship was described by:
$\sigma_{f}=A_{s} \frac{\left(\frac{V_{f}}{V_{f_{0}}}-1\right)}{\left(\frac{1}{V_{f}}-\frac{1}{V_{\alpha}}\right)^{4}}$,

where $\sigma_{f}$ is the compressive stress applied to the reinforcement, $V_{f_{0}}$ the original fibre volume fraction (i.e. when no compressive stress is applied), $V_{a}$ the available fibre volume fraction (i.e. when an infinite stress is applied) and $A_{s}$ is a "spring constant". This model was developed for the compaction of pre-preg material systems, and considers a lubricated unidirectional fibre bundle. Subsequent studies have shown this model to adequately capture the compaction behaviour of more complex reinforcements.

In 2003, Andersson et al. [31] linked $V_{f}$ to the compaction stress as follows:

$\sigma_{f}=k E\left(V_{f}^{m}-\left(V_{f_{0}}+\kappa\right)^{m}\right)$,

where $E$ is the stiffness of the fibres, $k$ and $m$ are constants derived from compaction measurements, and $\kappa$ accounts for the softening of the reinforcement (zero for a dry fabric and greater than zero for a wetted fabric). By using a double non-linear elastic behaviour, the authors were able to simulate the reinforcement lubrication effect occurring at the flow front. However the use of a model based on wet compaction for the filling stage is not rigorously correct, as during the filling stage the compaction stress on the preform decreases with time.

In 2005, Joubaud et al. [32] used in their RI simulation a compaction model similar to that used by Robitaille and Gauvin [33]

$V_{f}=a \sigma_{f}^{b}$,

where $a$ and $b$ are experimental parameters dependant on the reinforcement used. While it is not clearly stated in the paper, it appears that the authors have used a single compaction model based on wet compaction experiments. By using a single compaction model based on the wet reinforcement, the thickness (and permeability at the flow front) of the dry reinforcement was misrepresented, which may lead to an error in the progression of the flow front. It should also be noted that further error can be attributed to the use of a compaction model whereas, as mentioned, the reinforcement is actually subject to unloading during the filling stage of the process.

In 2008, Yenilmez et al. [34] used tabulated values of a dry compaction/dry unloading and dry compaction/wet unloading series of experiments in a presented simulation. After showing that there is a significant difference between the compaction and unloading traces, the authors then used the dry compaction data to determine the compaction of the reinforcement before the arrival of the fluid, and used the unloading data to simulate the thickness changes in the saturated part during the filling stage of the RI. Simulation re- 
sults were compared to filling experiments, demonstrating that significantly improved results were obtained using the dry compaction and wet unloading model. There is very little literature concerning experimentation and simulation of the post-filling stage of the RI process [25,35-37]. However, laminate thickness and resin pressure evolution during this stage determine the final quality of the resin infused part, and therefore need to be addressed.

Although some RTM and I/CM simulations have moved towards modelling more complicated reinforcement deformation [38-41], all reported RI simulations have applied one or two non-linear elastic compaction/unloading curves. Restricting the analysis to elastic modelling certainly reduces the complexity of the mechanical coupling which arises between the $V_{f}$ and the resin pressure. Also, due to the relatively slow cycle of compaction occurring in the RI process, a viscoelastic, i.e. inelastic, model might not be necessary or even appropriate.

This paper addresses the complex reinforcement deformation behaviour exhibited during the resin infusion process. A macroscale compaction model has been developed in conjunction with compaction experiments to replicate reinforcement behaviour during the pre-filling, filling and post-filling stages, through the use of multiple non-linear elastic curves. This model was then implemented into a Finite Element simulation of the infusion of a reinforcement without the aid of a distribution media. This case is industrially relevant, addressing infusion using a high permeability preform, as well as for RTM processes using inflatable bladders as B-side tools.

\section{Theory}

\subsection{Resin flow}

Resin flow through a fibrous reinforcement is usually described using Darcy's law, provided here for 1D flow in the $x$ direction;

$q_{x}=-\frac{K_{x x}}{\mu} \frac{d P}{d x}$

where $q_{x}$ represents the volume-averaged velocity, $K$ the permeability of the preform, $\mu$ the fluid viscosity and $P$ is the local fluid pressure. Considering both resin and fibres as incompressible, the conservation of solid and fluid mass imposes:

$-\frac{\partial\left(q_{x} h\right)}{\partial x}=\frac{\partial h}{\partial t}$

where $h$ is the local laminate thickness. Combining Eqs. (4) and (5) gives the governing equation;

$\frac{\partial}{\partial x}\left(\frac{K_{x x}}{\mu} h \frac{\partial P}{\partial x}\right)=\frac{\partial h}{\partial t}$.

Using a non-mixed method with conservative elements [42], $q_{x}$ at the flow front can be approximated as follows. Using linear finite elements, the first derivative of the pressure is constant over an element. Using a Taylor series about the centre of the element one finds that:

$q_{x}=-\frac{K_{x x}}{\mu} \frac{\partial P}{\partial x}+\left(x-x_{c}\right) \frac{\partial q_{x}}{\partial x}$.

As thickness and hence permeability varies spatially along the length, the velocity gradient can be expressed as:

$\left.\frac{\partial q_{x}}{\partial x}=\frac{\partial}{\partial x}\left(-\frac{K_{x x}}{\mu} \frac{\partial P}{\partial x}\right)=-\frac{1}{\mu} \frac{\partial K_{x x}}{\partial x} \frac{\partial P}{\partial x}+K_{x x} \frac{\partial^{2} P}{\partial x^{2}}\right)$,

and Eq. (6) can then be expanded to:

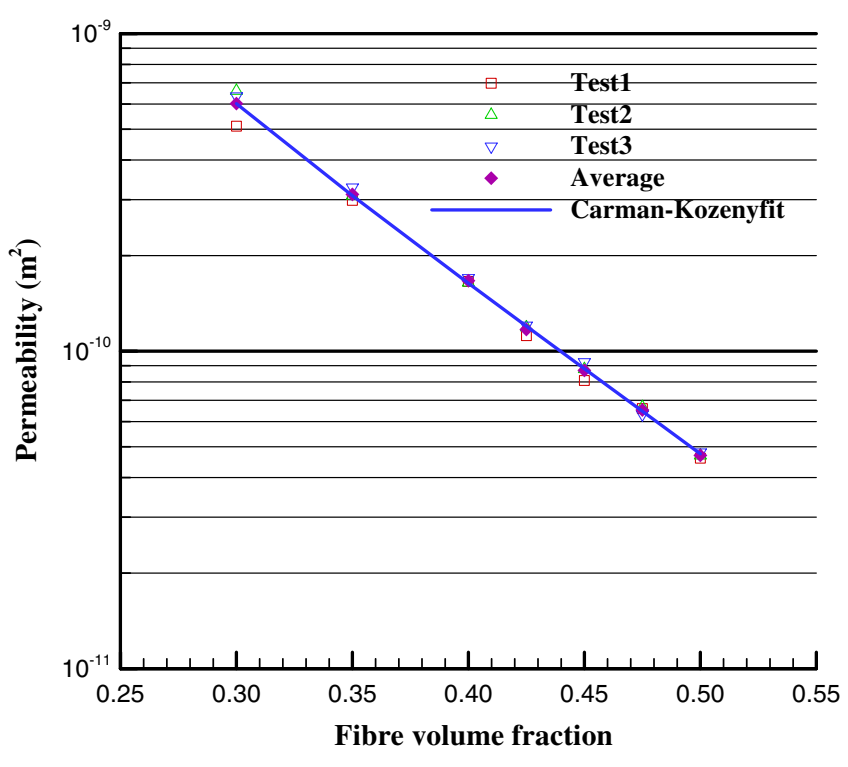

Fig. 2. Chopped strand mat permeability.

$\left.\frac{1}{\mu} \frac{\partial K_{x x}}{\partial x} \cdot h \cdot \frac{\partial P}{\partial x}+K_{x x} \cdot \frac{\partial h}{\partial x} \cdot \frac{\partial P}{\partial x}+K_{x x} \cdot h \cdot \frac{\partial^{2} P}{\partial x^{2}}\right)=\frac{\partial h}{\partial t}$.

Combining Eqs. (8) and (9) leads to:

$\frac{\partial q_{x}}{\partial x}=\frac{1}{h}\left(\frac{K_{x x}}{\mu} \frac{\partial h}{\partial x} \frac{\partial P}{\partial x}-\frac{\partial h}{\partial t}\right)$

The flow equation is therefore:

$q_{x}=-\frac{K_{x x}}{\mu} \frac{\partial P}{\partial x}+\left(\frac{x-x_{c}}{h}\right)\left(\frac{K_{x x}}{\mu} \frac{\partial h}{\partial x} \frac{\partial P}{\partial x}-\frac{\partial h}{\partial t}\right)$.

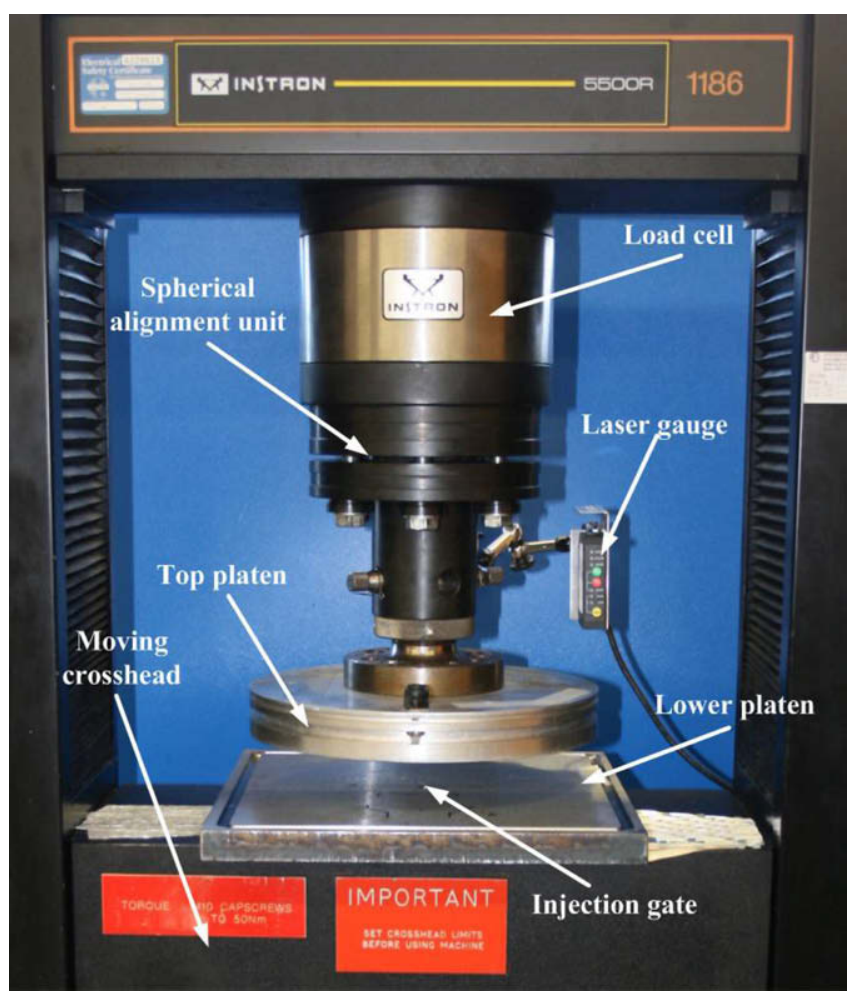

Fig. 3. Compaction characterisation experimental setup. 


\subsection{Reinforcement properties}

Local $V_{f}$ is dependant on the compaction stress history applied to the preform. As mentioned earlier, fibrous reinforcements have complex compaction behaviour, exhibiting viscoelasticity and permanent deformation $[33,38,43,44]$ and also display a change in stiffness between the dry and saturated state. During RI, fibre compaction is governed by the difference between external atmospheric pressure $\left(P_{a t m}\right)$ and pressure inside the cavity $(P)$, which is described by Terzaghi's relation [29]:

$\sigma_{f}=P_{a t m}-P$

In this study, the modified Carman-Kozeny equation is used to relate experimental permeability and $V_{f}$ data:

$K=C \frac{\left(1-V_{f}\right)^{n+1}}{V_{f}^{n}}$ where $C$ and $n$ are parameters determined from experiment. The permeability of the $450 \mathrm{~g} / \mathrm{m}^{2}$ Chopped Strand Mat (CSM) used this study was measured at various $V_{f}$ during steady state flow experiments following the procedure described by Umer et al. [45]. Three repeats of the test were performed showing very good repeatability, average $C$ and $n$ values found to be $9.5 \times 10^{-11} \mathrm{~m}^{2}$ and 2.6 , respectively. Fig. 2 presents permeability as a function of $V_{f}$ showing the experimental measurements as well as the modified Carman-Kozeny fit.

\section{Reinforcement compaction behaviour}

As discussed earlier, during RI, the reinforcement can be considered to follow three distinct compaction phases: a dry compaction during pre-filling, a wet unloading of the saturated region during filling and a wet re-compaction during post-filling. The characterisation of these compaction responses is discussed next.

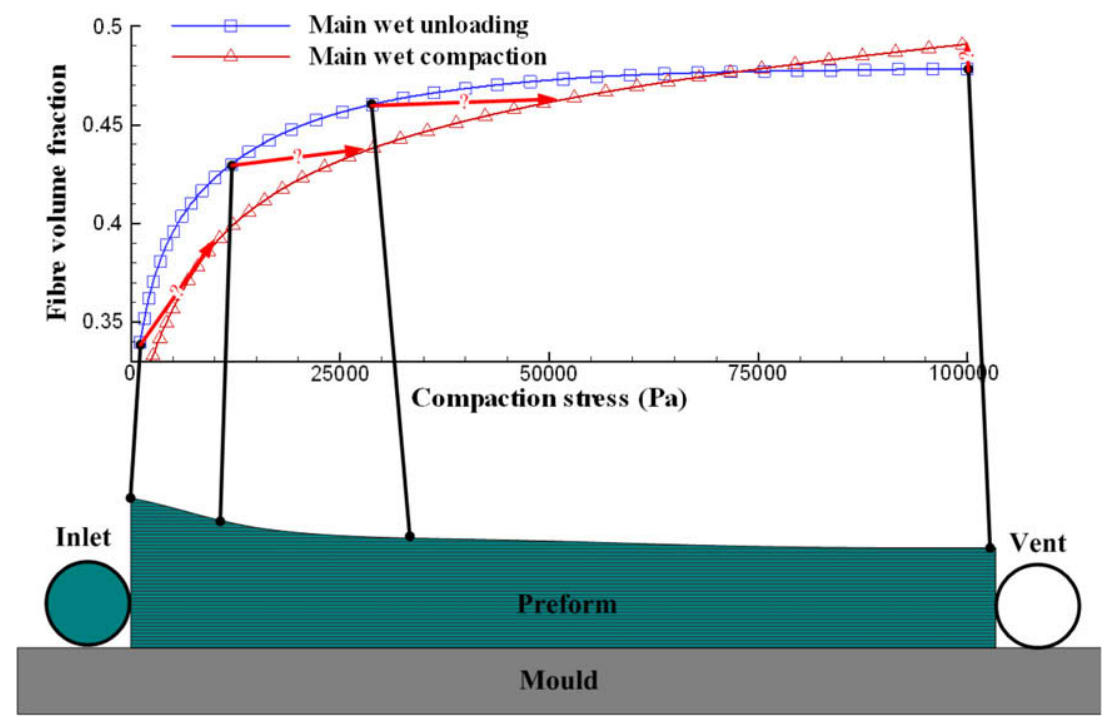

Fig. 4. Reinforcement compaction state at the completion of the filling stage.

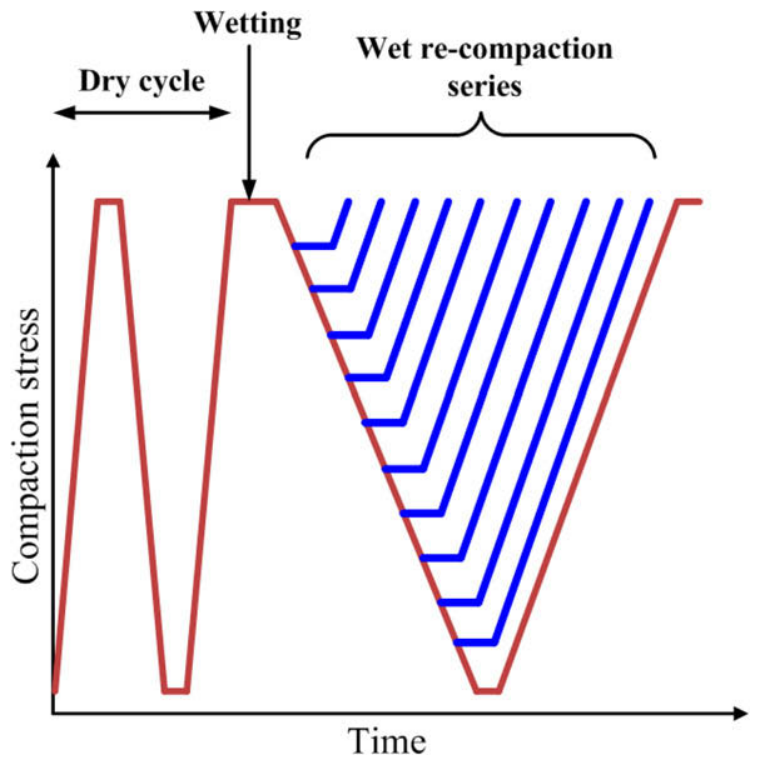

Fig. 5. Schematic description of the experimental compaction characterisation program.

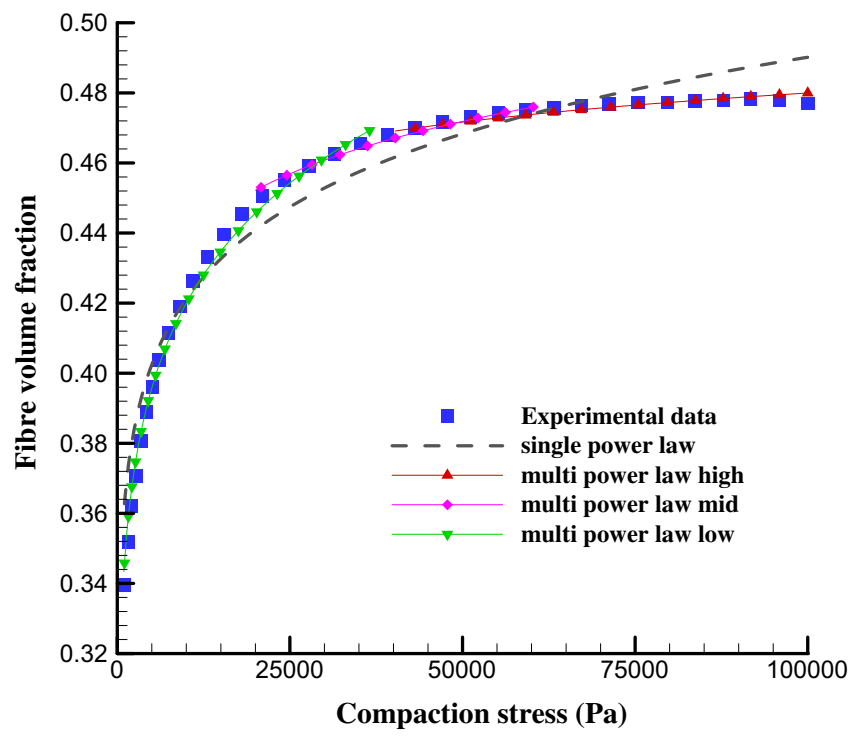

Fig. 6. Example fitting of experimental compaction trace. The application of three curves is compared to application of a single power law curve. 


\subsection{Experimental procedure}

Compaction behaviour of the CSM has been experimentally characterised using an Instron universal testing machine in force control mode, using a rig composed of two flat platens. The upper platen is fitted with a spherical alignment system to minimise misalignment with the lower platen (Fig. 3). The reinforcement samples were composed of ten layers cut into $200 \mathrm{~mm}$ diameter disks with a $15 \mathrm{~mm}$ diameter hole at their centre.

To simulate dry compaction occurring during the pre-filling stage, each sample was compacted at a rate of $0.3 \mathrm{kN} \mathrm{min}^{-1}$ to an equivalent compaction pressure of 1.0 bar. This pressure was then maintained for 5 min to allow for any significant creep to occur. The sample was then unloaded to an equivalent pressure of 0.01 bar, again held for $5 \mathrm{~min}$ to allow for creep, and then reloaded to 1.0 bar at the same rate of $0.3 \mathrm{kN} \mathrm{min}^{-1}$. It is this second, reloaded, compaction curve which is used for the dry compaction curve. This was done in order to replicate the compaction history during pre-filling, for which vacuum is first applied and then slowly released while looking for leaks in the bag. This procedure is commonly applied in industry before final application of vacuum prior to the filling stage. The sample was then wetted while compacted by injecting mineral oil through the centre of the lower platen, mimicking the wetting process at the flow front. The fluid was injected at a pressure of $1.8 \mathrm{bar}$ until the sample was completely saturated, the injection time being typically less than $2 \mathrm{~min}$. After waiting for $8 \mathrm{~min}$ to allow for creep to occur, the saturated sample was then unloaded to an equivalent pressure of 0.01 bar at a rate of $0.05 \mathrm{kN} \mathrm{min}^{-1}$. This replicates the reduction of compaction stress applied to the preform during the filling stage where the resin pressure inside the cavity increases. To replicate the post-filling stage, the saturated sample was then re-compacted to an equivalent pressure of 1.0 bar at a rate of $0.05 \mathrm{kN} \mathrm{min}^{-1}$. During this wet compaction phase, the fluid pressure at the injection gate was monitored. No significant pressure build up was detected due to the choice of fluid viscosity, loading rate and sample size. From this point on, the wet unloading to $0.01 \mathrm{bar}$, will be referred as the "main wet unloading" and the wet compaction from 0.01 bar will be referred as the "main wet compaction".

During an actual resin infusion process, at the completion of filling there exists a gradient of fluid pressure ranging from approximately atmospheric pressure at the inlet, to the applied vacuum pressure at the vent. Therefore, the compaction state of the preform at the completion of filling varies along the length of the part from stress-free at the inlet to 1.0 bar of compaction stress at the vent. The inlet is typically closed at the onset of post-filling, while the excess fluid is being drawn through the vent from this point in time. As a result, the fluid pressure inside the laminate decreases, thus increasing the compaction stress on the fibres.

As described in $[33,46,47]$, reinforcement compaction behaviour is dependant on the compaction history. The reinforcement at the inlet, being fully unloaded at the completion of filling, will behave differently to that closer to the vent, which is still partially compacted. Fig. 4 schematically depicts the reinforcement compaction state along the length of the preform at the completion of the filling stage and presents experimental traces of the main wet unloading and main wet compaction behaviour. At the onset of post-filling, the material has undergone a wet unloading but, due to the pressure profile along the preform, an unloading to different volume fractions along the length of the preform. This is indicated by the black lines linking different points of the preform to the main wet unloading trace in Fig. 4 As post-filling proceeds, the material is next wet compacted. However, one cannot use

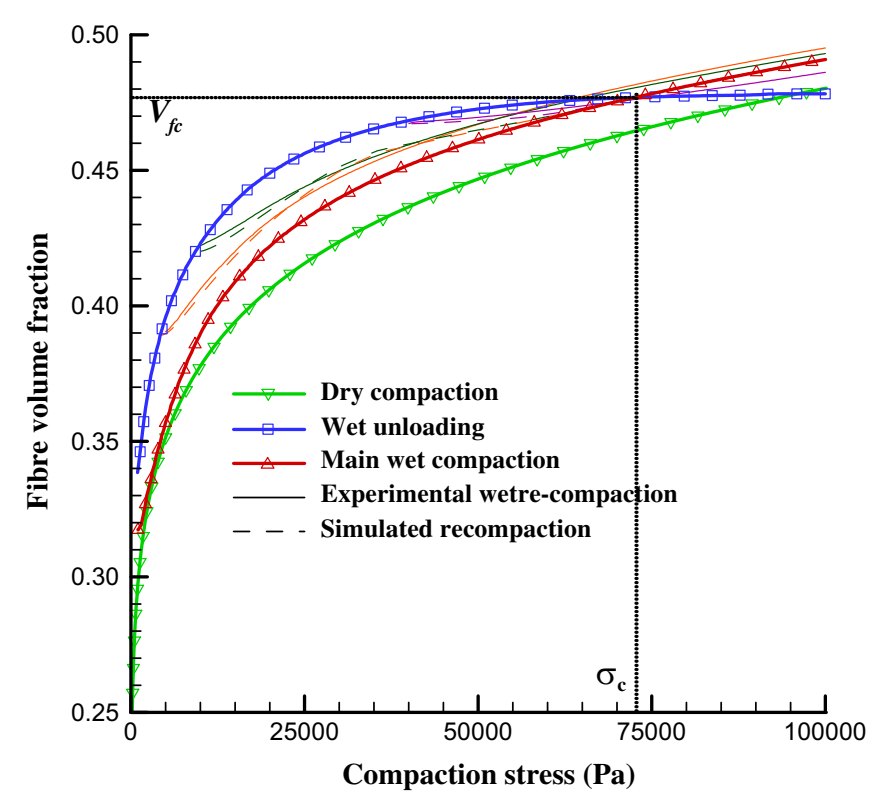

Fig. 7. Comparison of re-compaction model and experimental results.

the main wet compaction data (shown by the red ${ }^{1}$ line in Fig. 4) directly. This is because that data was obtained after a complete unloading (zero stress), whereas the material during post-filling is actually re-compacted from non-zero stress-states (as indicated by the red arrows in Fig. 4), moving towards the main wet compaction as post-filling progresses. To map the compaction response during this period, another series of tests were therefore conducted in which the samples were first compacted and wetted under similar conditions as described above. Unlike the first tests, the samples were then unloaded to various compaction levels and then re-compacted to an equivalent pressure of 1 bar at a rate of $0.05 \mathrm{kN} \mathrm{min}^{-1}$. Fig. 5 schematically describes the series of tests performed to evaluate the influence of the compaction history. During each test the dry cycle is similar but, after wetting, the sample is unloaded to different levels before being re-compacted.

\subsection{Numerical interpolation}

To fit the experimental data using simple equations, the data were first divided into three non-linear elastic laws; dry compaction, main wet unloading and main wet compaction. It was found that a power law (14) as described by Robitaille $[33,46]$ was an effective way of characterising the relationship between stress and fibre volume fraction. The following power law can be easily inverted and differentiated, and provides a reasonable fit to the experimental data:

$V_{f}=V_{f_{0}} \cdot \sigma_{f}^{B}$,

where $V_{f_{0}}$ and $B$ are parameters determined from experiment.

To obtain a closer fit to the experimental data over the complete $V_{f}$ range, the experimental compaction and unloading traces were interpolated in three overlapping sections. Fig. 6 presents an example of this approach, comparing fitting of the wet unloading data by a single power law and by three overlapping power laws. A macro has been written within Microsoft Excel to optimise the selection of the sections to interpolate. This macro minimises the fitting error as well as the change of gradient between the

\footnotetext{
${ }^{1}$ For interpretation of color in Fig. 4, the reader is referred to the web version of this article.
} 
interpolated curves. The dry compaction, wet unloading to $0.01 \mathrm{bar}$, and wet compaction from 0.01 bar experimental traces were interpolated following this approach.

\subsection{Re-compaction after partial unloading}

As could be expected, all of the partial wet unloading traces follow the main wet unloading trace. A difficulty lies in modelling the wet re-compaction behaviour, as each trace starts from a different point on the main unloading trace. To be of any use in a simulation, it is necessary to be able to determine the re-compaction behaviour from any arbitrary unloading pressure with a minimum number of equations. It was found that the compaction of the partially unloaded preform can be interpolated from the main wet unloading and main wet compaction models as follows:

$$
V_{f_{R}}\left(\sigma_{f}, \sigma^{*}\right)= \begin{cases}\min \left\{\begin{array}{l}
V_{f_{U}}\left(\sigma_{f}\right)-\left(\frac{\left(\sigma_{C}-\sigma_{f}\right) \cdot\left(V_{f_{U}}\left(\sigma_{f}\right)-V_{f_{L}}\left(\sigma_{f}\right)\right)}{\left(\sigma_{C}-\sigma^{*}\right)} \cdot \frac{\sigma_{f}-\sigma^{*}}{\sigma_{f}}\right) \\
V_{f_{L}}\left(\sigma_{f}\right)+\left(\frac{\left(\sigma_{C}-\sigma_{f}\right)}{\left(\sigma_{C}-\sigma^{*}\right)} \cdot\left(V_{f_{U}}\left(\sigma_{f}\right)-V_{f_{L}}\left(\sigma_{f}\right)\right)\right)
\end{array}\right. & V_{f}<V_{f_{C}}, \\
V_{f_{L}}(P) & V_{f} \geqslant V_{f_{C}}\end{cases}
$$

with $\sigma^{*}$ the compaction stress on the reinforcement at the start of the re-compaction, $V_{f_{R}}$ the volume fraction during the re-compaction, $V_{f_{U}}$ the volume fraction following the main wet unloading trace, $V_{f_{L}}$ the volume fraction following the main wet compaction trace, $V_{f_{C}}$ and $\sigma_{C}$ are the fibre volume fraction and compaction stress at which the main wet compaction and unloading curves are found to intersect. It was also observed that all the re-compaction traces crossed the unloading curve around that point. This point has significance in the definition of the proposed compaction model, while at this time the physical significance is not clearly understood. If $V_{f} \geqslant V_{f_{c}}$ the model uses the main wet compaction trace. If $V_{f}<V_{f_{C}}$ the model uses the minimum produced by two approaches to interpolation between $V_{f_{U}}$ and $V_{f_{L}}$. The first interpolation gave best results at compaction stresses close to $\sigma^{*}$, while the second was found to be more accurate as the compaction stress was increased.

Fig. 7 presents the experimental CSM dry compaction, main wet unloading, main wet compaction and a selection of three re-compaction curves. Also presented are re-compaction curves generated using the interpolation described by Eq. (15). From Fig. 7 we can see that the model is in very good agreement with the experiment for compaction stresses below $\sigma_{C}$.

For $\sigma>\sigma_{C}$ the re-compaction model follows the main wet compaction trace, resulting in moderate errors.

\section{Simulation}

Having discussed the compaction behaviour, next is discussed a complete 1D simulation of the RI process which includes this compaction information.

\subsection{Solution method}

Using the Galerkin Finite Element Method, the weak formulation of Eq. (6) is:

$\int_{x_{i}}^{x_{i+1}}\left(\left(\frac{K_{x x}}{\mu} h \frac{\partial p}{\partial x} \frac{d \omega}{d x}\right)+\frac{\partial h}{\partial t} \omega(x)\right) d x=\left[\frac{K_{x x}}{\mu} h \frac{\partial P}{\partial x} \omega(x)\right]_{x_{i}}^{x_{i+1}}$.

To assemble this formulation on the computational mesh, it is first formulated in the matrix form:

$\overline{K(\bar{h})_{e l}}+\overline{\overline{C_{e l}}} \frac{\partial \bar{h}}{\partial t}=\overline{F(\bar{h})_{e l}}$ where $\overline{K(\bar{h})_{e l}}$ is the element stiffness vector, $\overline{\overline{C_{e l}}}$ the element capacitance matrix, $\overline{F(\bar{h})_{e l}}$ the element force vector, and $\bar{h}$ is the vector of laminate thickness values associated with the element. An implicit method is used by applying a backward difference approximation:

$\frac{\partial h}{\partial t} \approx \frac{h(t)-h(t-\Delta t)}{\Delta t}$.

The current thickness values $(h(t))$ are estimated from the previous time step, and an iterative approach has been taken to refine the solution. Eq. (17) can then be expressed as:

$\left.\overline{K(\overline{h(t)})}+\overline{\bar{C}} \frac{\overline{h(t)}-\overline{h(t-\Delta t)}}{\Delta t}\right)=\overline{F(\overline{h(t)})}$,

where $\overline{h(t)}$ and $\overline{h(t-\Delta t)}$ are the vectors of laminate thickness throughout the filled part of the mould at time $t$ and $t-\Delta t$, respectively. The estimated error is the residual, $\overline{R(h(t))}$, calculated from:

$\overline{R(h(t))}=\overline{\bar{C}}(\overline{h(t)}-\overline{h(t-\Delta t)})+\Delta t(\overline{K(\overline{h(t)})}-\overline{F(\overline{h(t)})})$.

To minimise the residual at each time step, the Newton-Raphson algorithm is used.

$\left[\overline{\overline{K_{T}\left(\overline{h^{i-1}}\right)}}\right] \cdot \overline{\Delta h^{i}}=-\overline{R\left(\overline{h^{i-1}}\right)}$,

$\overline{\overline{K_{T}\left(\overline{h^{i-1}}\right)}}=\left.\frac{\partial \bar{R}}{\partial \bar{h}}\right|_{h^{i-1}}$,

$\overline{h^{i}}=\overline{h^{i-1}}+\overline{\Delta h^{i}}$

The matrix $\overline{\overline{K_{T}}}$ is the tangent matrix, $i$ the iteration number and $h^{i}$ is the vector of thickness distribution at iteration $i$. For the first iteration, the thickness distribution is assumed equal to the thickness distribution at the previous time step. This algorithm is run iteratively until the residual reaches the desired precision.

\subsection{Boundary conditions}

The presented simulation uses a 1D mesh with linear elements. At both inlet and vent, additional elements are used to simulate the resin distribution tape applied in these regions. This feature allows for more accurate simulation of the conditions at the entry and exit of the fluid to and from the preform. During filling, the inlet node has a prescribed fluid pressure, and the flow front node is set to the applied vacuum pressure at the vent. During post-filling, to model clamping of the inlet tube, the inlet node is assigned a zero

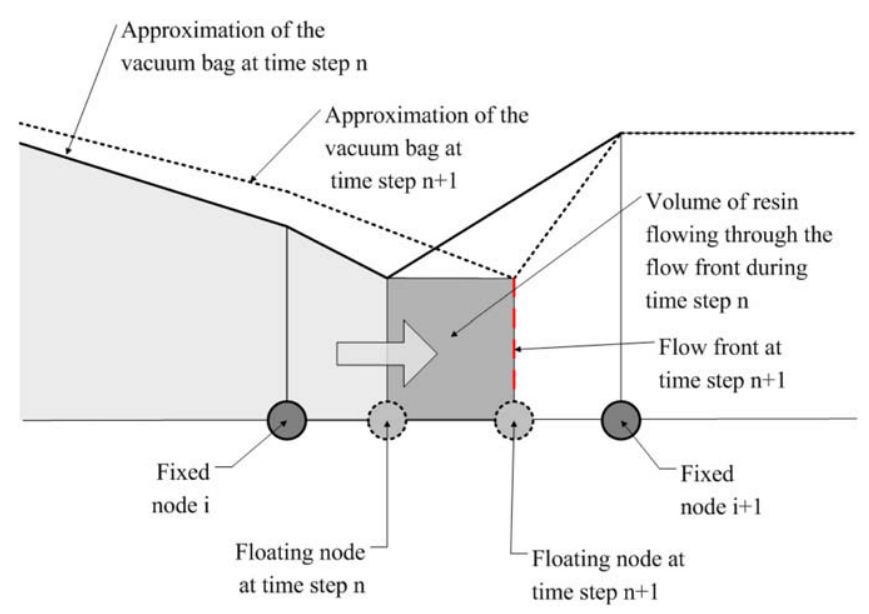

Fig. 8. Schematic diagram of the use of the floating node. 


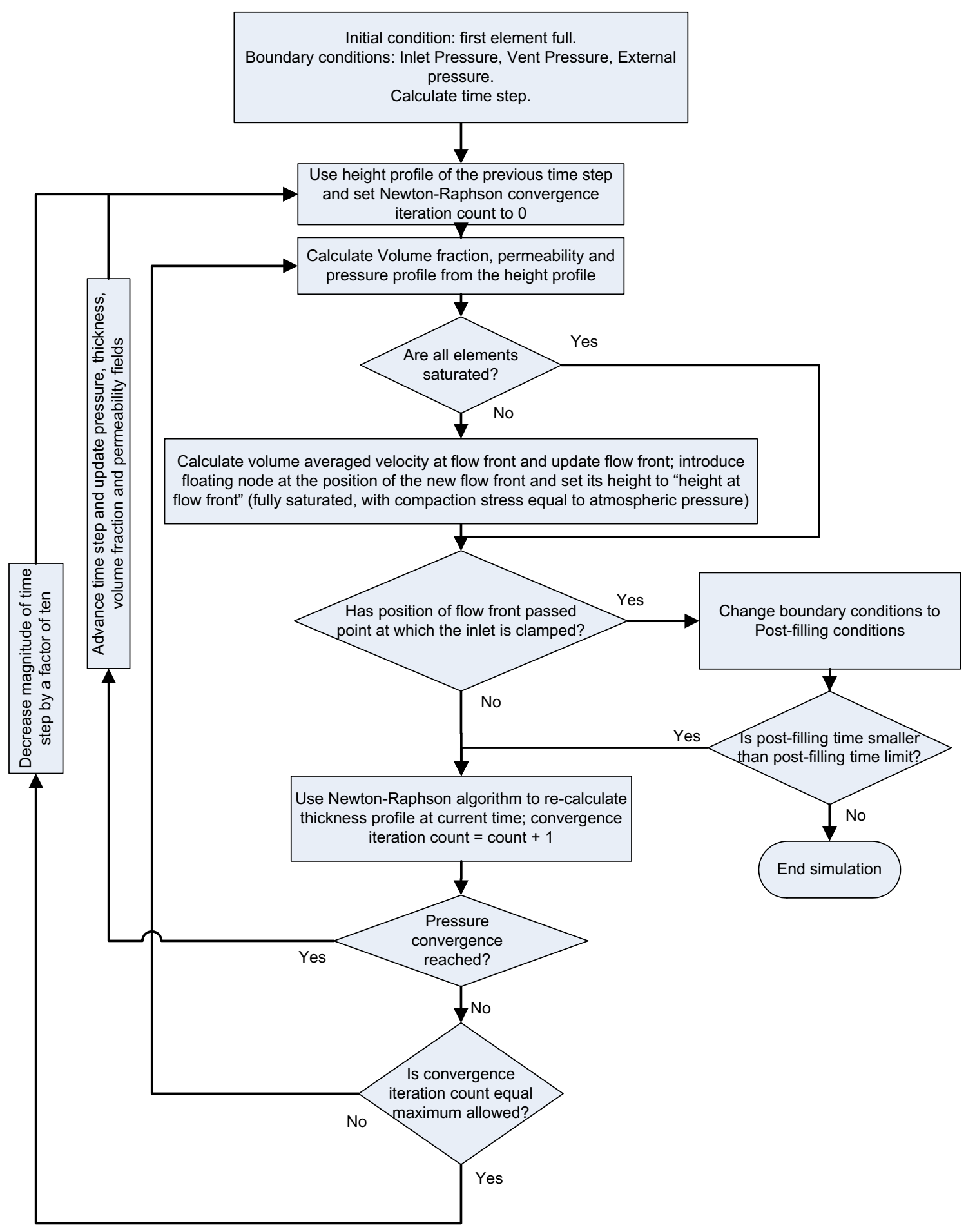

Fig. 9. Flow chart description of the simulation.

Table 1

Plan of simulations.

\begin{tabular}{|c|c|c|c|c|}
\hline Scenario & Description & $\begin{array}{l}\text { Flow front position at the } \\
\text { end of filling }(\mathrm{mm})\end{array}$ & Brake & Post-filling pressure (mbar) \\
\hline Case 1 & Standard & 400 & No & 4.7 \\
\hline Case 2 & Use of brake & 400 & 5 mm peel-ply & 4.7 \\
\hline Case 3 & Modified post-filling pressure & 400 & No & 200 \\
\hline Case 4 & Early inlet clamp & 340 & No & 4.7 \\
\hline
\end{tabular}


pressure gradient. The flow front node pressure is maintained at a constant vacuum pressure.

\subsection{Floating node}

The preform is discretised using a grid of fixed nodes. To allow for accurate tracking of the flow front without penalising computational performance, a floating node, i.e. a node temporarily placed between two of the fixed grid nodes, is used; the floating node marks precisely the flow front. Fig. 8 demonstrates the application of the floating node. At the start of time step $n$ the laminate thickness profile is known, and therefore the $V_{f}$, permeability and fluid pressure along the cavity. The flow front velocity is then calculated from the pressure gradient at the flow front. The new position of the flow front is then approximated, assuming its velocity remains constant throughout the time step. The floating node is then moved to this new position and the laminate thickness profile is calculated using the iterative Newton-Raphson implicit method.

\subsection{Solution process}

A complete summary of the simulation and solution procedure is given in the flow chart of Fig. 9. As the reinforcement compaction behaviour is assumed to be purely elastic, the pre-filling stage of the simulation is of minor importance. The laminate properties at the end of pre-filling and in the dry portion of the preform are those of the dry reinforcement under a load equivalent to the atmospheric pressure minus the vacuum pressure. The initial conditions are calculated with the first element filled, the quasi-static height profile and flow rate being determined in that region. Using the fluid velocity at the flow front, the flow front is updated and the Newton-Raphson algorithm is used to calculate the new temporary properties of the saturated part of the preform. The algorithm is declared converged when the fraction of thickness change is smaller than the set convergence criteria. If the algorithm converges in less than a specified upper limit on iterations, the time step is advanced and the pressures and preform properties are updated. Otherwise the values at the beginning of the time step are retrieved and the solution is evaluated for a smaller time step.

The filling stage is complete once the flow front reaches the specified position, or alternatively once a specified quantity of fluid is injected. Once the end of filling condition is achieved, the boundary conditions are changed to those of post-filling. The iterative process remains the same as for the filling. If the flow front reaches the end of the mesh, the amount of resin evacuated is calculated from the flow out of the last element. The simulation is set to run for a given post-filling time period, typically comparable to the gel time of the applied resin system.

Once all the steps of the simulation were finalised, convergence tests were performed to verify the convergence of the simulation and find the most efficient mesh size and convergence criteria. To test the convergence of the solution, the evolution of the predicted fill time was evaluated as a function of the number of elements as well as the convergence criteria. It was found that convergence was reached with a 100 elements mesh and a convergence criteria of $1.0 \times 10^{-5}$.

\section{Simulation results}

To demonstrate the capability of the presented compaction model and RI simulation, four different infusion scenarios are considered. In each case the goal was to impregnate a $400 \mathrm{~mm}$ long preform consisting of 10 layers of CSM, the fluid used in each case is considered to be mineral oil Mobil DTE Heavy, with a constant Newtonian viscosity of $0.365 \mathrm{~Pa} \mathrm{~s}^{-1}$.
The first case considered is a "standard" infusion in which the preform is infused completely before clamping the inlet and letting the excess resin flow through the vent during post-filling. The second case uses $5.0 \mathrm{~mm}$ width of peel-ply as a "brake" between the end of the preform and the vent. A third example applies a change in the vacuum pressure during post-filling. The final scenario demonstrates simulation of the inlet being clamped early, the inlet is clamped once the flow front has progressed along $85 \%$ of the length of the cavity, and the excess resin in the saturated portion of the preform is used to complete filling. Details of the four simulated scenarios are given in Table 1.

\subsection{Material parameters}

The preform simulated was composed of 10 layers of the previously characterised CSM, and was $200 \mathrm{~mm}$ wide and $400 \mathrm{~mm}$ long. At the inlet side a groove $5 \mathrm{~mm}$ high having a length of $5 \mathrm{~mm}$ was simulated, providing a flow channel with a constant equivalent permeability of $2.5 \times 10^{-6} \mathrm{~m}^{2}$, based on calculations for flow between to infinite parallel plates. At the vent side of the preform a high permeability distribution tape $5 \mathrm{~mm}$ thick with a length of $20 \mathrm{~mm}$ was simulated, having a permeability of $7.5 \times 10^{-7} \mathrm{~m}^{2}$ and a porosity of 0.85 . For case 2 , a single layer of peel-ply was simulated at the vent end, with a permeability of $7.5 \times 10^{-11} \mathrm{~m}^{2}$, a thickness of $0.1 \mathrm{~mm}$ and a porosity of 0.3 .

It should be noted that apart from the CSM, the material parameters chosen here are rough estimates based on experimental observation and equivalent permeability calculations. These materials require more careful characterisation in order to provide numerical results comparable to actual experiments. The authors acknowledge that the brake case is an extreme virtual scenario, in real industrial application a "brake" zone may commonly consist of a felt material. Such a brake would have a lower permeability but higher porosity and thickness, and would also be longer in length. The authors have chosen a $5 \mathrm{~mm}$ peel-ply brake to illustrate the potential of the simulation and highlight the importance of enabling fluid to flow through.

\subsection{Comparing RI and RTM filling simulations}

For the first three scenarios considered, the conditions during filling are unchanged. It is interesting to compare the flow front advancement predicted by the resin infusion simulation with an analytical solution for RTM. An RTM solution considers a rigid mould with constant prescribed laminate thickness. Fig. 10 presents the progression of the flow front calculated by the RI simula-

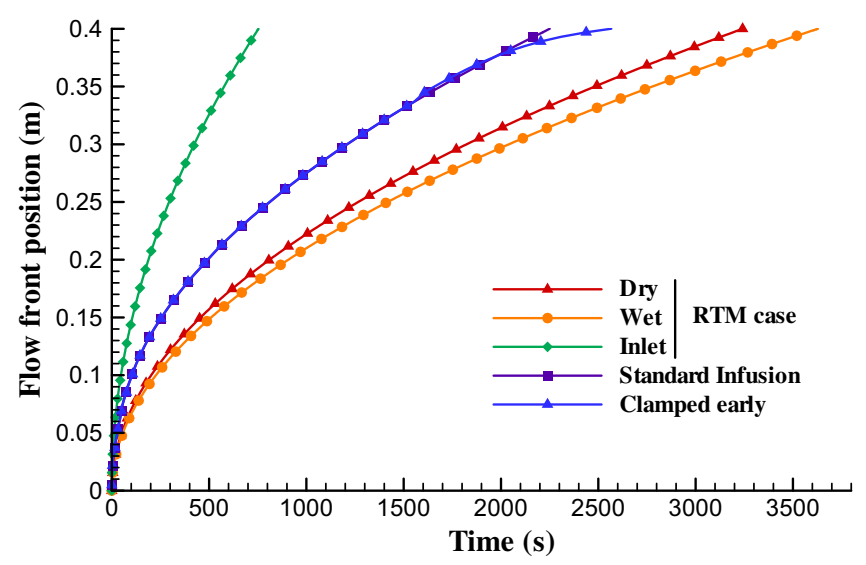

Fig. 10. Evolution of flow front position, comparison between RTM and resin infusion simulations. 
tions corresponding to case 1 and case 4, with comparison to three RTM cases. For the 'Dry case', laminate thickness is derived from the dry CSM compaction, with applied compaction equivalent to 1.0 bar. The 'Wet case' simulation uses the wet CSM compaction data at the same compaction level. The 'Inlet case' uses the measured laminate thickness at the inlet at the completion of filling, i.e. thickness of a saturated reinforcement with no applied compac- tion stress. The RTM 'Dry' and 'Wet' solutions significantly over estimate the fill time, as they do not account for increases in permeability in the saturated portion of the preform. The RTM 'Inlet case' greatly underestimates the fill time, as an overly large cavity thickness is used, within which permeability is significantly larger than experienced in reality. For RI simulation case 4 (inlet clamped early) we can observe the flow front progressively slowing down as
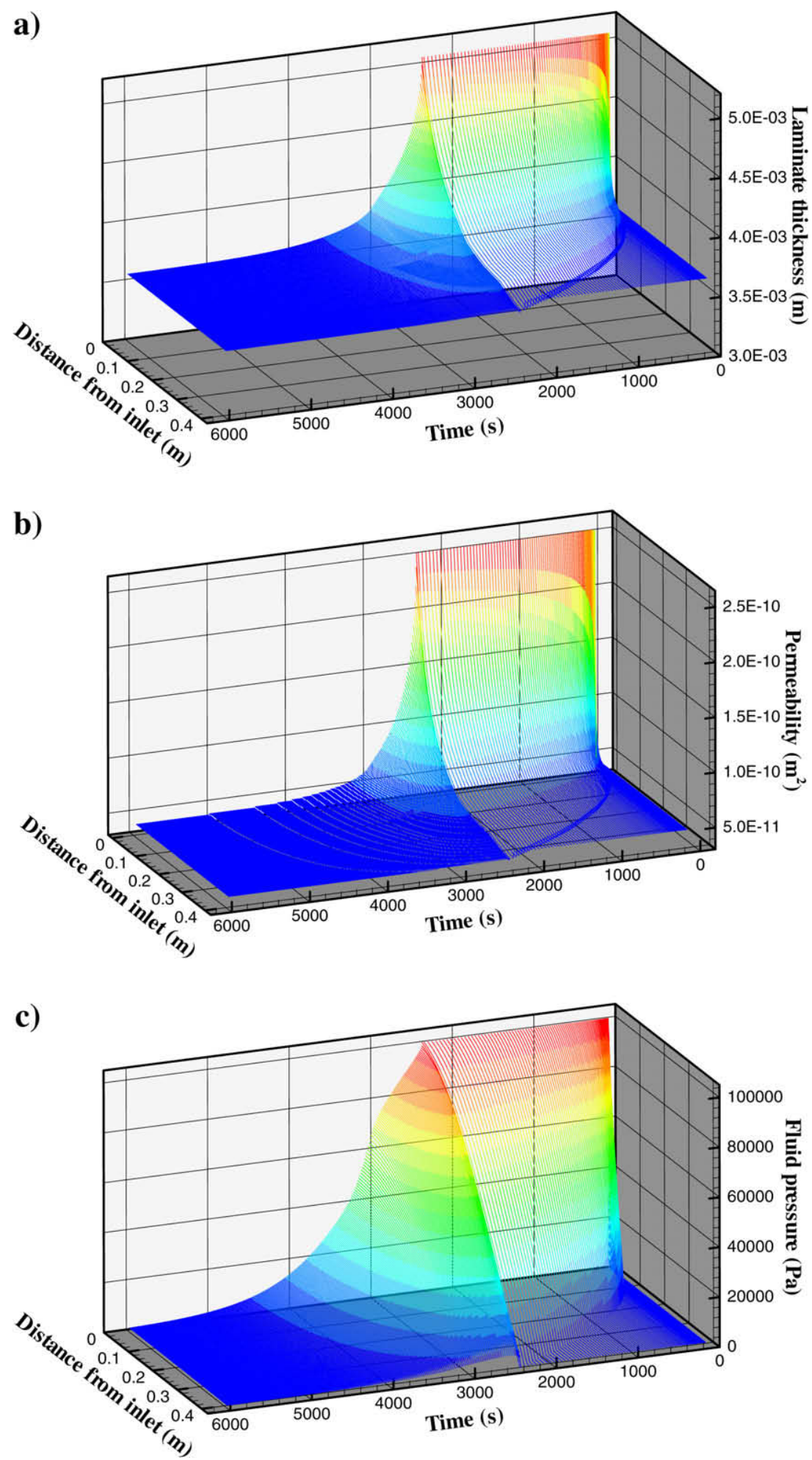

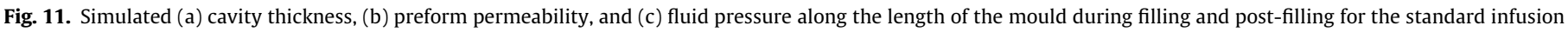
(case 1 ). 
the pressure gradient inside the laminate reduces, the flow front reaching the end of the preform $300 \mathrm{~s}$ later than in the other RI solutions ( $\sim 13 \%$ longer).

Fig. 11a-c present, respectively, the laminate thickness, laminate permeability and fluid pressure along the length of the preform during both filling and post-filling for the "standard" infusion strategy, case 1 . Surface plots have been used to efficiently present the variation of each quantity in time, and along the length of the perform. Each line on a plot represents the distribution of the observed variable along the preform length at one time step during the process. From Fig. 11b it can be seen that there is a very large predicted variation of permeability in the inlet half of the preform, this again illustrating the importance of accounting for thickness changes in an RI filling simulation.
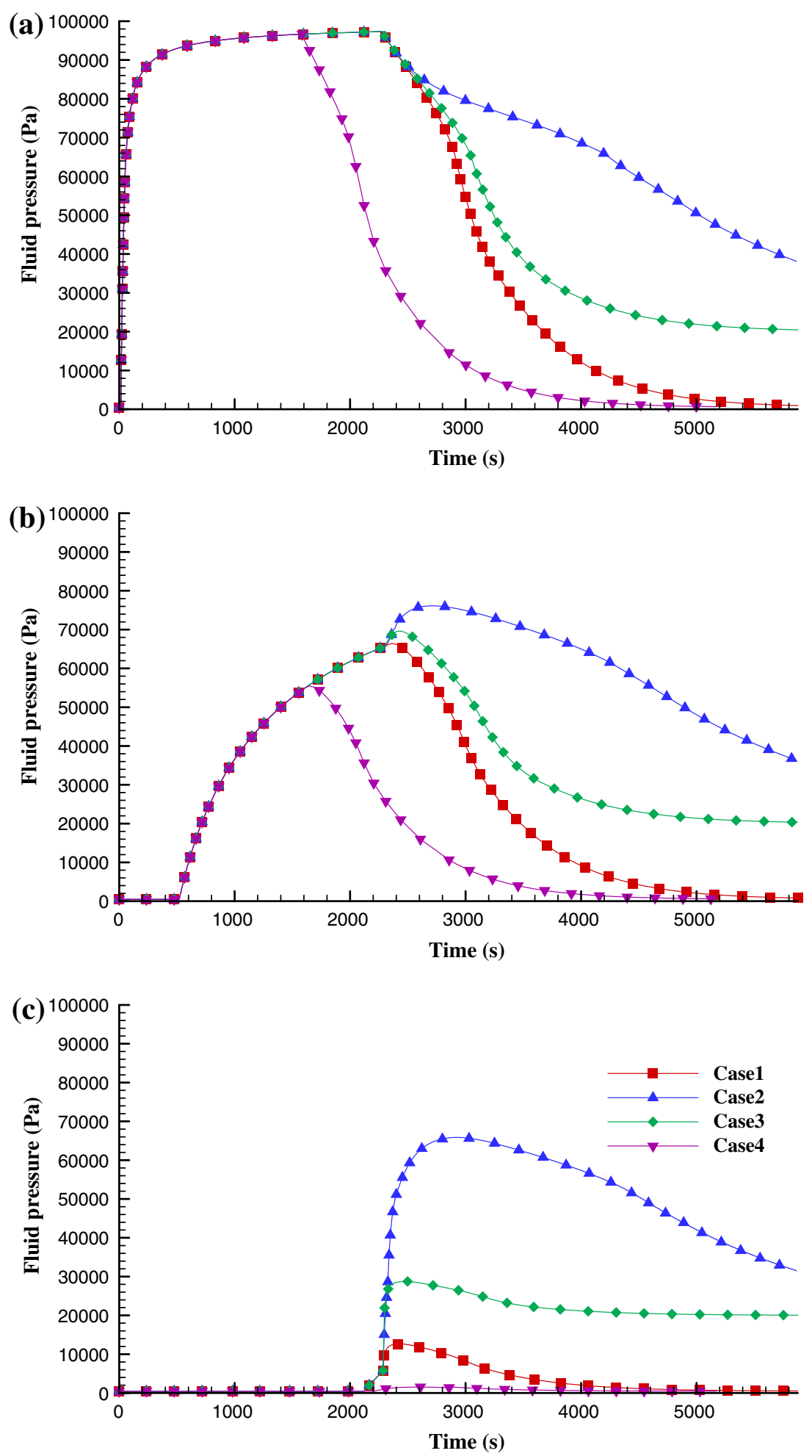

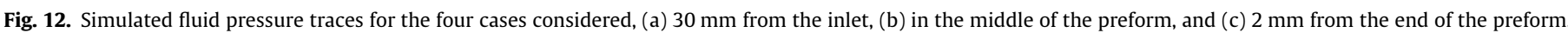




\subsection{Comparing the resin infusion cases}

Figs. 12 and 13 present the simulated resin pressure and laminate thickness evolutions for the four RI cases. In both figures the values are evaluated at three points along the length of the laminate $30 \mathrm{~mm}$ away from the inlet, at the centre of the preform and $2 \mathrm{~mm}$ away from the end of the preform. For the case where the inlet was clamped early (case 4), the pressure and laminate thickness reach equilibrium much earlier than for the three other cases. In this case, less fluid was introduced into the cavity, resulting in a lower amount of excess fluid to be evacuated through the vent. The next case to reach equilibrium is that in which the post-filling pressure was set to 200 mbar (case 3). In this case less fluid was evacuated as the equilibrium fluid pressure was set to a higher value.
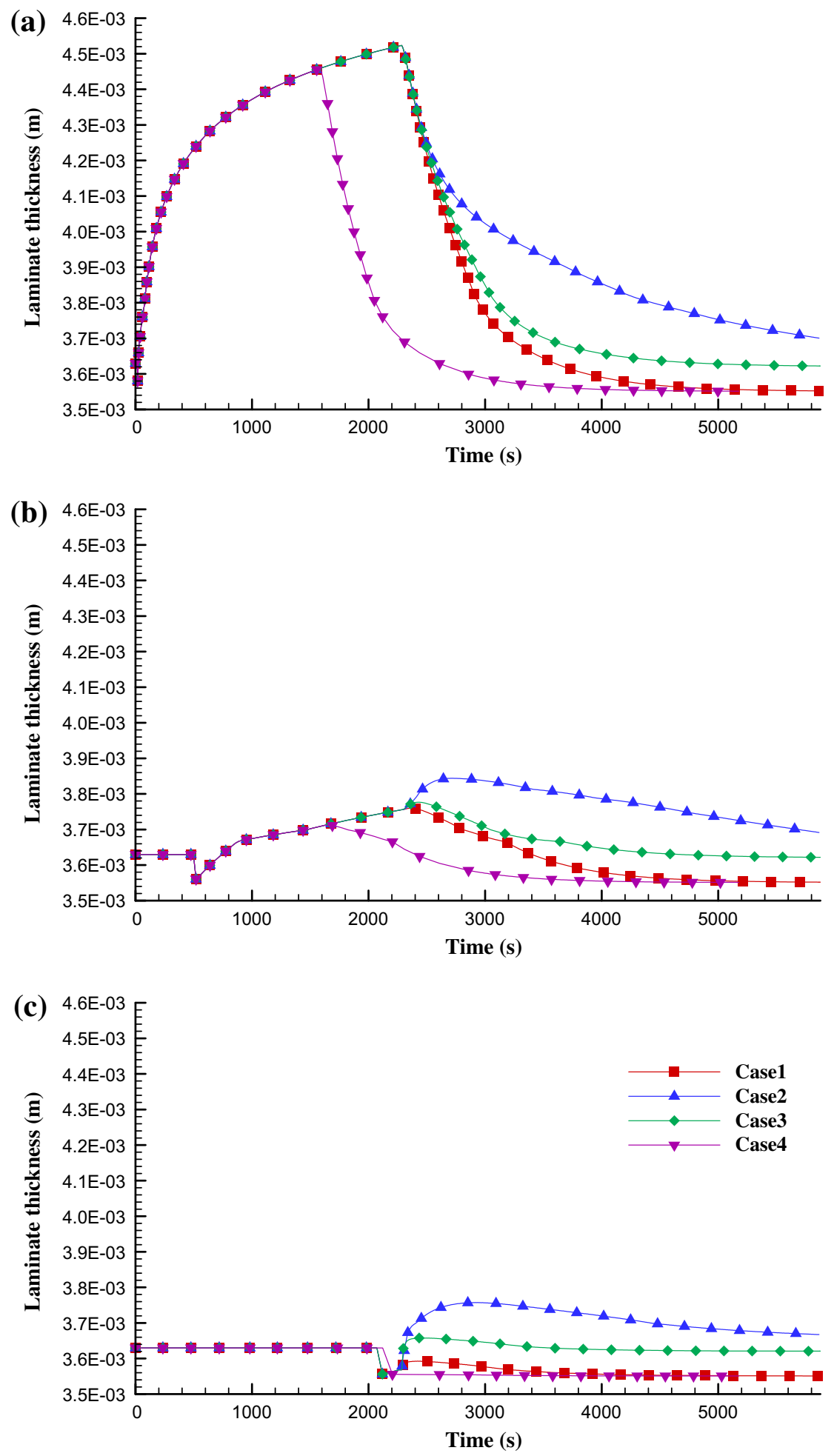

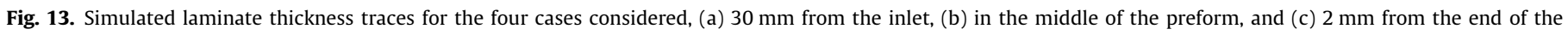
preform. 
In case 2 , the brake material had a similar permeability as the CSM but a much smaller thickness and porosity, thus severely limiting the quantity of fluid able to flow through this material. The reduction of pressure and laminate thickness during post-filling was therefore considerably slower than for any other case. This case was the only one in which the preform had not reached equilibrium after $1 \mathrm{~h}$ of simulated post-filling. This result demonstrates the strong influence of additional flow resistances placed between the preform and vent, a practice commonly applied in industry.

In cases 2 and 3 , the changes of condition at the flow front at the end of filling have a significant effect on resin pressure and laminate thickness close to the vent and approaching the centre of the preform. In both cases the resin flow rate at the flow front is predicted to slow down creating a pressure build up at the end of the preform. This, in conjunction with the squeeze flow occurring at the inlet side, result in a rise of pressure between the vent and the middle of the preform. In the case for which post-filling vent pressure is set to 200 mbar, the flow front stops briefly until the fluid pressure behind the flow front increases over $200 \mathrm{mbar}$, then the rest of the post-filling happens at a similar rate as for case 1. In case 2 however, the flow of fluid through to the vent is perturbed by the small amount of fluid able to flow through the peel-ply at any time, there is therefore a pressure build up at the end of the preform. The fluid pressure along the preform tends to equalise leaving only a small gradient related to the slow flow of fluid through the brake material.

In an industrial RI process, the aim will typically be to have a low cycle time with the best possible part quality. It is therefore desirable for the resin pressures within the laminate to have equalised before gelation of the resin system. For this reason cases 3 and 4 could be considered as preferable approaches. It should be noted that at very low pressure levels, many thermoset resin systems tend to release gases as components boil off, leading to increased porosity in the part. In the case in which the inlet is clamped early, fluid pressures decrease quickly to a very low level, thus increasing the risk of porosity developing in the laminate. In case 3 , as the equilibrium pressure is set to a higher value, this problem may be avoided, but the predicted final fibre volume fraction will be slightly lower than in the other cases $(0.48$ for case 3 instead of 0.49 for cases 1 and 4 ).

In industrial applications a brake zone is usually applied between the end of the preform and the vent. This brake is intended to slow down the flow of resin and insure the whole part is impregnated before the resin reaches the vent. As can be seen from the simulation of case 2, the choice and dimension of the brake material is very influential on the post-filling stage. In this case, progression of the flow front was slowed only slightly, however the rate of extraction of the excess resin was dramatically reduced. A better strategy would have been to choose a material with a lower permeability but a higher porosity and larger thickness, which would have slowed down the progression of the flow front while not limiting the resin flow rate out of the preform.

\section{Conclusion}

In this paper we have demonstrated an interpolated method to model the through thickness deformation behaviour of a CSM reinforcement during the resin infusion process. This model includes a variation of the empirical multiple power law model previously developed by Robitaille [46], as well as an interpolation method to account for the loading history of the preform. The model predictions were in good agreement with the tests carried out with the Instron universal testing machine.

The compaction model was then implemented into a onedimensional Finite Element simulation of the resin infusion pro- cess, addressing the pre-filling, filling and post-filling stages. The predictions during post-filling are promising, this simulation showing the potential for predicting fibre volume fraction in the final part, as well as simulating different injection strategies (i.e. clamping of the inlet before the flow front reaches the end of the preform, or changing vacuum pressures during post-filling). The ability to simulate applied post-filling conditions may lead to an optimisation of the pressure parameters and choice of brake material, increasing part quality and control of $V_{f}$, while reducing cycle time.

\section{Acknowledgements}

The authors would like to acknowledge the generous support of the Foundation for Research, Science and Technology, New Zealand. We would also like to thank High Modulus (NZ), Nuplex Industries Ltd. and Aurora Glass Fibre (NZ) Ltd. for their support of this research.

\section{References}

[1] Modi D, Correia N, Johnson M, Long A, Rudd C, Robitaille F. Active control of the vacuum infusion process. Compos Part A: Appl Sci Manuf 2007;38(5):1271-87.

[2] Berenberg B. Liquid composite molding achieves aerospace quality. HighPerform Compos 2003;11(6):18-22.

[3] Lawrence JM, Fried P, Advani SG. Automated manufacturing environment to address bulk permeability variations and race tracking in resin transfer molding by redirecting flow with auxiliary gates. Compos Part A: Appl Sci Manuf 2005;36(8):1128-41.

[4] Leonard-Williams S. The crossover from RTM to resin infusion. Reinf Plast 2008:52(10):28-9.

[5] Lin RJ, Lee JL, Liou MJ. Mold filling and curing analysis in liquid composite molding. Polym Compos 1993;14(1):71-81.

[6] Liu B, Bickerton S, Advani SG. Modelling and simulation of resin transfer moulding (RTM)-gate control, venting and dry spot prediction. Compos Part A: Appl Sci Manuf 1996;27(2):135-41.

[7] Lin M, Thomas Hahn H, Huh H. A finite element simulation of resin transfer molding based on partial nodal saturation and implicit time integration. Compos Part A: Appl Sci Manuf 1998;29:541-50.

[8] Mohan RV, Ngo ND, Tamma KK. On a pure finite-element-based methodology for resin transfer molds filling simulations. Polym Eng Sci 1999;39(1):26-43.

[9] Gokce A, Advani SG. Simultaneous gate and vent location optimization in liquid composite molding processes. Compos Part A: Appl Sci Manuf 2004;35(12):1419-32.

[10] Simacek P, Advani SG. Desirable features in mold filling simulations for liquid composite molding processes. Polym Compos 2004;25:355-67.

[11] Soukane S, Trochu F. New remeshing applications in resin transfer molding. J Reinf Plast Compos 2005;24(15):1629-53.

[12] Bickerton S, Advani SG. Characterization and modeling of race-tracking in liquidcomposite molding processes. Compos Sci Technol 1999;59(15): 2215-29.

[13] Bickerton S, Sozer EM, Graham PJ, Advani SG. Fabric structure and mold curvature effects on preform permeability and mold filling in the RTM process. Part II. Predictions and comparisons with experiments. Compos Part A: Appl Sci Manuf 2000;31(5):439-58.

[14] Dimitrovova Z, Advani SG. Mesolevel analysis of the transition region formation and evolution during the liquid composite molding process. Comput Struct 2004;82(17-19):1333-47.

[15] Deleglise M, Binetruy C, Krawczak P. Simulation of LCM processes involving induced or forced deformations. Compos Part A: Appl Sci Manuf 2006;37(6):874-80

[16] Bickerton S, Abdullah MZ. Modeling and evaluation of the filling stage of injection/compression moulding. Compos Sci Technol 2003;63(10):1359-75.

[17] Lee DH, Lee WI, Kang MK. Analysis and minimization of void formation during resin transfer molding process. Compos Sci Technol 2006;66(16):3281-9.

[18] Devillard M, Hsiao K-T, Advani SG. Flow sensing and control strategies to address race-tracking disturbances in resin transfer molding - part II: automation and validation. Compos Part A: Appl Sci Manuf 2005;36(11): 1581-9.

[19] Ferland P, Guittard D, Trochu F. Concurrent methods for permeability measurement in resin transfer molding. Polym Compos 1996;17(1):149-58.

[20] Luo Y, Verpoest I, Hoes K, Vanheule M, Sol H, Cardon A. Permeability measurement of textile reinforcements with several test fluids. Compos Part A: Appl Sci Manuf 2001;32(10):1497-504.

[21] Turner DZ, Hjelmstad KD. Determining the 3D permeability of fibrous media using the Newton method. Compos Part B: Eng 2005;36(8):609-18.

[22] Liu Q, Parnas RS, Giffard HS. New set-up for in-plane permeability measurement. Composites Part A: Applied Science and Manufacturing 2007;38(3):954-62. 
[23] Buntain MJ, Bickerton S. Compression flow permeability measurement: a continuous technique. Compos Part A: Appl Sci Manuf 2003;34(5):445-57.

[24] Correia NC, Robitaille F, Long AC, Rudd CD, Simacek P, Advani SG. Analysis of the vacuum infusion moulding process: I. Analytical formulation. Compos Part A: Appl Sci Manuf 2005;36(12):1645-56.

[25] Govignon Q, Bickerton S, Morris J, Kelly PA. Full field monitoring of the resin flow and laminate properties during the resin infusion process. Compos Part $A$ : Appl Sci Manuf 2008;39(9):1412-26.

[26] Hammami A, Gebart BR. Analysis of the vacuum infusion molding process. Polym Compos 2000;21(1):28-40.

[27] Kang MK, Lee WI, Hahn HT. Analysis of vacuum bag resin transfer molding process. Compos Part A: Appl Sci Manuf 2001;32:1553-60.

[28] Williams C, Summerscales J, Grove S. Resin infusion under flexible tooling (RIFT) : a review. Compos Part A: Appl Sci Manuf 1996;27(7):517-24.

[29] Terzaghi K. Theoretical soil mechanics. New York: John Wiley and Sons; 1943.

[30] Gutowski TG, Morigaki T, Cai Z. The consolidation of laminate composites. J Compos Mater 1987;21:172-88.

[31] Andersson HM, Lundstrom TS, Gebart BR. Numerical model for vacuum infusion manufacturing of polymer composites. Int J Numer Methods Heat Fluid Flow 2003;13(3):383-94.

[32] Joubaud L, Achim V, Trochu F. Numerical simulation of resin infusion and reinforcement consolidation under flexible cover. Polym Compos 2005;26(4):417-27.

[33] Robitaille F, Gauvin R. Compaction of textile reinforcements for composites manufacturing. I: Review of experimental results. Polym Compos 1998;19:198-216.

[34] Yenilmez B, Senan M, Murat Sozer E. Variation of part thickness and compaction pressure in vacuum infusion process. Compos Sci Technol 2009;69(11-12):1710-9.

[35] Simacek P, Advani SG. Modeling resin flow and fiber tow saturation induced by distribution media collapse in VARTM. Compos Sci Technol 2007;67(13):2757-69.

[36] Robinson MJ, Kosmatka JB. Resin bleeding simulation for the VARTM process. In: Proceedings of SAMPE 2008 conference. Long Beach, CA.
[37] Kuentzer N, Simacek P, Advani SG, Walsh S. Correlation of void distribution to VARTM manufacturing techniques. Compos Part A: Appl Sci Manuf 2007;38(3):802-13

[38] Somashekar AA, Bickerton S, Bhattacharyya D. Exploring the non-elastic compression deformation of dry glass fibre reinforcements. Compos Sci Technol 2007;67(2):183-200.

[39] Comas-Cardona S, Le Grognec P, Binetruy C, Krawczak P. Unidirectional compression of fibre reinforcements. Part 1: a non-linear elastic-plastic behaviour. Compos Sci Technol 2007;67(3-4):507-14.

[40] Kelly PA, Umer R, Bickerton S. Viscoelastic response of dry and wet fibrous materials during infusion processes. Compos Part A: Appl Sci Manuf 2006;37(6):868-73.

[41] Saunders RA, Lekakou C, Bader MG. Compression in the processing of polymer composites 2. Modelling of the viscoelastic compression of resin-impregnated fibre networks. Compos Sci Technol 1999;59:1483-94.

[42] Kelly PA, Jennings S. Nonconforming elements for liquid composite molding processes. In: Proceedings of FPCM8 Conference. Douais, France; July 2006. p. 315-21.

[43] Grimsley BW, Hubert P, Song X, Cano RJ, Loos AC, Pipes RB. Flow and compaction during the vacuum assisted resin transfer molding process. SAMPE; 2001.

[44] Kessels JFA, Jonker AS, Akkerman R. Fully 2 1/2D flow modeling of resin infusion under flexible tooling using unstructured meshes and wet and dry compaction properties. Compos Part A: Appl Sci Manuf 2007;38(1):51-60.

[45] Umer R, Bickerton S, Fernyhough A. Characterising wood fibre mats as reinforcements for liquid composite moulding processes. Compos Part A: Appl Sci Manuf 2007;38(2):434-48.

[46] Robitaille F, Gauvin R. Compaction of textile reinforcements for composites manufacturing. II: Compaction and relaxation of dry and $\mathrm{H} 20$ saturated woven reinforcements. Polym Compos 1998;19:543-57.

[47] Robitaille F, Gauvin R. Compaction of textile reinforcements for composites manufacturing. III: reorganization of the fiber network. Polym Compos 1999;20(1):48-61. 